Preprints of the

Max Planck Institute for

Research on Collective Goods

Bonn 2006/19

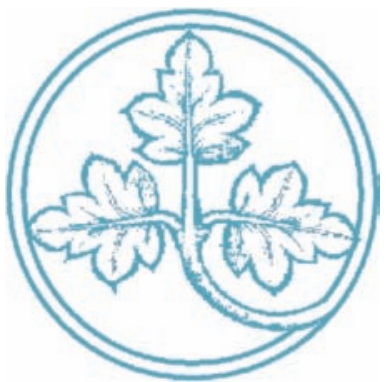

The Impact of Institutions on the Decision How to Decide

Christoph Engel /

Elke U. Weber

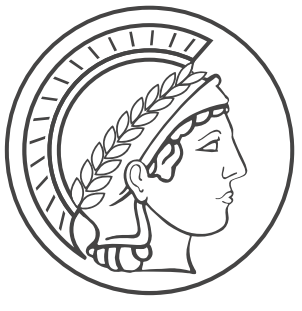




\title{
The Impact of Institutions on the Decision How to Decide
}

\author{
Christoph Engel / Elke U. Weber
}

July 2006 


\section{The Issue}

Institutions are constraints, rational choice institutionalists say (e.g. Furubotn and Richter 1997). Institutions are social constructions, holistic institutionalists say (e.g. March and Olsen 1989). Try to use either of these major concepts of an institution to understand why we have driver's licences. Of course, you may be fined if stopped by the police and not in possession of your driver's license. Yet this constraint is but one element of a much richer institutional arrangement. And while hardly anybody would quarrel with the obligation of all drivers to go to driving school, the effect of this institution on social construction also only scratches the surface.

Admittedly, there are many more attempts at defining institutions, and at explaining their social function (Hodgson 1988; DiMaggio and Powell 1991; Rutherford 1994; Hall and Taylor 1996; DiMaggio 1998; Nee 1998; Peters 1999; Mantzavinos 2001; Ostrom 2005; Hodgson 2006). One class of them is much better prepared to address the driving school example, namely those that link institutions to habit formation (Veblen 1898; Langlois 1998; Loasby 1999:chapter 3; Nooteboom and Bogenrieder 2003; Hodgson 2004). The existence of habits and the ability of institutions to shape habits is indeed central to the conceptual framework for the effect of institutions described in this paper, though the framework is not confined to habits. It invites institutionalists to consider not simply the effect(s) of institutions (like mandatory driving school) on observable behaviour, but to also see them as ways of shaping the processes by which individuals subjected to those institutions decide on or generate behaviour.

Whether by design or incidentally, institutions serve a purpose. Driving school serves at least four of them simultaneously. Untrained drivers pose a risk to other drivers, bystanders and passengers. Training thus reduces negative externalities. Schooling also makes it less likely that drivers injure themselves or damage their own car. The requirement of a driving license thus has a paternalistic dimension. Moreover, standardised training makes drivers predictable. One need for instance not be afraid that those coming from the other side of the junction will ignore the red traffic light. Thereby local interaction is facilitated. Finally, learners are also taught to be responsive to traffic lights, traffic signs and the orders of policemen. That way, driving school increases what Lawrence Lessig has dubbed regulability (Lessig 1999).

These four outcomes are the ultimate goals of regulating driver competence. To reach these ultimate goals, the regulator must attain two proximate goals. New drivers must be endowed with the socially desirable set of driving routines, and they must be induced to use them whenever they get on the road. Driving a car is a complex task. Drivers must know how to physically handle the car while properly responding to the features of the road and, most importantly, the behaviour of other drivers. A mere legal obligation to drive "adequately" would not produce the desired behaviour, no matter how serious the sanction attached to its violation. Only after they have built the appropriate habits, are drivers able to behave as necessary for street safety.

To bring this result about, the legal system needs an entire institutional arrangement. There is indeed a sanction, as required by the rational choice approach to institutions, as a policeman has 
power to fine any driver unable to produce a valid driver's license. This ensures that future drivers first go to driving school and pass a driving test. The actual training is a mixture of theory and practice under the supervision of a driving instructor. Part of the training is learning a large set of cues, ranging from the stoplights of other cars and oil on the street to a wide range of traffic signs, as well as the appropriate behaviour in different situations. The associations between environmental cues and appropriate behaviour are repeatedly practiced, until they are sufficiently automatised.

The example illustrates our message to institutional analysts and designers. Institutions are frequently unable to immediately and directly reach their ultimate goal of moving the behaviour of its addressees into a socially desired direction. They can only do so if they first reach the proximate goal of changing their addressees' decision how to decide. Even in situations where institutional designers could directly target behaviour by just one intervention, e.g. through ostensibly raising stakes, they may prefer this more indirect approach. The addressees' decision how to decide thus constitutes an independent access point for institutional intervention. Moreover it provides institutional designers with an opportunity for time shifting. They may impact on the addressees' repertoire of techniques for decision-making long before they take the first socially relevant decision in a domain. This may be desirable since intervention at the moment when a change in behaviour is needed may entail a larger opportunity cost for either the regulator or the addressee.

The remainder of this article is organised as follows: Section 2 briefly describes psychological research on multiple modes of decision making that is the starting point for the model offered in the current paper. Section 3 develops an informal model of multiple modes of problem-solving and their selection in any given situation. Based on this model, Section 4 characterises access points for institutional intervention into the decision how to decide or how to solve a problem. Section 5 concludes.

\section{Deciding how to Decide: Multiple Modes of Making Decisions}

Changing the addressees' decision how to decide only makes sense if individuals possess more than one mental tool for the purpose. This is indeed the case. Table 1 summarizes the taxonomy (Weber 1998; Weber and Lindemann 2007) have developed for the purpose. 


\begin{tabular}{|c|c|c|c|c|}
\hline Mode & Sub Type & Inputs & Processes & Motivational Focus \\
\hline calculation & cost-benefit & $\begin{array}{l}\text { - } \text { attributes } \\
\text { - probabilities }\end{array}$ & $\begin{array}{l}\text { - evaluation of options } \\
\text { - comparison }\end{array}$ & $\begin{array}{l}\text { maximisation of } \\
\text { material outcomes }\end{array}$ \\
\hline \multirow[t]{3}{*}{ recognition } & case-based & holistic situations & $\begin{array}{l}\text { - pattern matching } \\
\text { - execution of if-then } \\
\text { productions }\end{array}$ & $\begin{array}{l}\text { - } \text { technical } \\
\text { efficiency } \\
\text { - accuracy }\end{array}$ \\
\hline & rule-based & $\begin{array}{l}\text { situational ele- } \\
\text { ments that trigger } \\
\text { rule }\end{array}$ & $\begin{array}{l}\text { - explicit category- } \\
\text { sation } \\
\text { - execution of if-then } \\
\text { productions }\end{array}$ & $\begin{array}{l}\text { - "doing the right } \\
\text { thing" } \\
\text { - fairness } \\
\text { - justifiability } \\
\text { - self control }\end{array}$ \\
\hline & role-based & $\begin{array}{l}\text { situational } \\
\text { elements relevant } \\
\text { to social role }\end{array}$ & $\begin{array}{l}\text { - recognition of role- } \\
\text { related expectations } \\
\text { - execution }\end{array}$ & $\begin{array}{l}\text { - } \text { connectedness } \\
\text { - social identity } \\
\text { - self-esteem }\end{array}$ \\
\hline affect & wants & $\begin{array}{l}\text { aroused physio- } \\
\text { logical state }\end{array}$ & $\begin{array}{l}\text { - } \text { positive/negative } \\
\text { associations } \\
\text { (classic conditioning) } \\
\text { - learned approach or } \\
\text { avoidance response } \\
\text { (operant conditioning) }\end{array}$ & $\begin{array}{l}\text { - fulfilment of wants } \\
\text { - self-affirmation } \\
\text { - autonomy }\end{array}$ \\
\hline
\end{tabular}

Table 1

Decision Modes

The taxonomy distinguishes three classes of decision modes: calculation-based, affect-based, and recognition-based decisions, captured colloquially as decisions made by the head, by the heart, and by the book. The three classes of decision modes differ in the situational inputs and the psychological processes they utilize. Calculation-based decisions involve analytical thought. Affectbased decisions are based on immediate, holistic, affective reaction (Epstein 1994; Damasio 2000). In recognition-based decision-making, the decision-maker recognises the situation as a member of a class for which a satisfactory action is known (Simon 1990).

Recognition-based decisions come in different variants. In case-based decisions, the decisionmaker is typically an expert in the decision domain, with a memory store of specific decision situations and their appropriate associated actions. These mental representations can be thought of as IF-THEN productions, where the IF element is a set of conditions that must be met in order to trigger the resultant action represented by the THEN part of the production. The expert decision-maker is able to unconsciously apply these production rules that have been developed through repeated experience, as demonstrated by (Klein 1998) with experts such as firefighters and jet pilots.

Another type of recognition-based decisions are rule-based decisions. These rules may be laws (IF you are driving and come to a red light, THEN you must stop) or other types of regulations (parental rules, selfimposed admonishments, societal norms, or company rules) (Prelec and Herrnstein 1991). In role-based decisions, the decision context elicits a rule of conduct that derives from a social role of the decision-maker (March and Heath 1994). As a mother, IF your child is very ill, THEN you must stay home and care for him. 
(Weber 1998; Weber and Lindemann 2007) propose that these different modes of making decisions coexist because each mode is better suited than others to address different human needs and motives. Calculation-based modes are best suited to maximize material consequences. Someone wanting to justify her decisions to a supervisor would be well-served by making her decision in a rule-based fashion. Role-based decisions serve to satisfy the motives of connectedness and affiliation. The need for autonomy may be best met by using an affect-based decision mode, as a way of affirming that one's personal desire for an action suffices.

Multiple modes of processing have been well documented for a wide variety of tasks. The (Payne, Bettman et al. 1988; Payne, Bettman et al. 1993) adaptive decision maker program showed that people strategically employ a wide range of decision strategies in the context of multi-attribute choice (e.g., which car to purchase). More recent work has demonstrated the strategic use of a toolbox of strategies in inference tasks (Gigerenzer and Selten 2001) and for decision mode selection (Weber and Hsee 2000; Weber, Ames et al. 2004). The idea of a plurality of mental tools is also captured by dual process theories (Evans and Over 1997; Chaiken and Trope 1999; Stanovich and West 2000; Bohner 2001). These models claim that the human mind has two processing modes, one more analytic and reflective, the other more automatic and impulsive, that operate in parallel and can both compete and cooperate with each other (Strack and Deutsch 2002).

The agenda of this paper goes beyond previous psychological research in its assumptions about the social context of decisions and actions. Exceptions like (Bandura 1986) notwithstanding, psychological studies typically concentrate on behaviour in standardised contexts. In reality however, context is often shaped or even provided by institutions. Another shortcoming of the adaptive theory of decision mode selection is that it addresses the implicit selection of one or more ways of deciding between a set of choice options, rather than the more ill-defined situations more commonly encountered outside of the laboratory that are better described as problem solving tasks. When describing the work of managers, scientists, engineers, or lawyers, (Simon 1986) distinguished between decision making and problem solving in the following way. He referred to the activities of fixing agendas, setting goals, and designing actions as problem solving, and to activities of evaluating and choosing between alternative actions as decision making.

There are some precursors, though none very close, to the goal of the present paper to understand how institutions affect and influence the mental processes by which behaviour is generated. Closest in intention and coverage is work that explores the interaction between institutions and behaviour not generated by deliberate reasoning, with a focus primarily on routines or habits (James 1893:143; Veblen 1898:390; Hodgson 1988:123-134; Vanberg 2002; Hodgson 2004). The legal literature on addiction normally takes it as a given that institutions must step in to overcome socially or individually detrimental decision modes without being concerned about how this is or can be done; a symposium bringing psychologists and legal philosophers together on this topic has been an interesting exception (Corrado 1999). Recently, there has also been interest in the interaction between heuristic decision making and the law (Gigerenzer and Engel 2006), and in institutional interventions that increase predictability. Predicting the behaviour of 
an interaction partner is difficult precisely because the human mind is not just one general problem solving machine. Not the least reason for this is the plurality of decision modes (Engel 2005). The literature on heuristics and biases, with recommendations for debiasing (for a summary account see Jolls and Sunstein 2006) also considers a related issue, but typically focuses on the direct effect of institutions on behaviour, not on the more indirect strategy of targeting the mental mechanism by which this behaviour is generated.

\section{A Model of Problem Solving Modes}

\section{a) The Basic Model}

Models cannot be right or wrong. A model is good if it has high explanatory or predictive power. The benchmark for evaluating the utility of a model thus depends on the research question. The question explored in this paper is how institutions impact on the decision how to decide. For institutional designers this is, however, only the proximate goal. We need a model that links this proximate goal to the ultimate goal of changing behaviour such that social betterment is achieved. Our model may therefore not be confined to what happens inside the mind. It must link tasks to mental machinery. Figure 1 displays the basic components of our model.

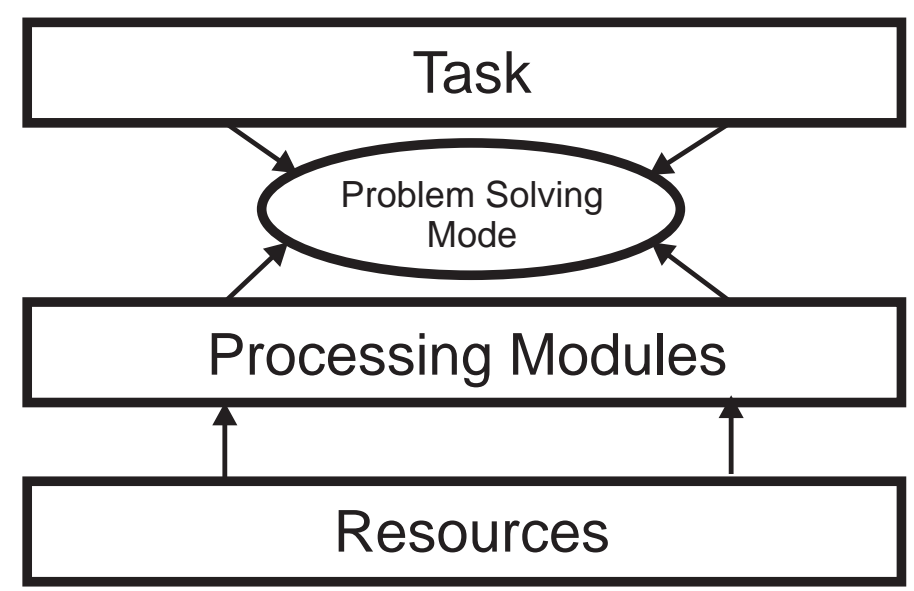

Figure 1

Problem Solving Model

Individuals rely on problem solving modes when faced with a decision task. While the problem solving mode used in a given situation may be designed on the spot, we assume that it is usually preconfigured. (See Table 2 below for some illustrations.) If so, the decision how to solve the problem at hand converts into choosing an appropriate mode from the stock of problem solving modes. Problem solving modes rely on processing modules. Standard modules are informational input, the design of a response, and the generation of an output. Each of the modules has recourse to appropriate resources for fulfilling its functional task. For instance, if information is 
visual, the eye and brain regions needed for processing the sensory input are activated to translate the picture on the retina into meaningful information about the environment.

Not all problem tasks are equal. If you spot a poisonous snake twenty yards away, being fast is paramount. If your boyfriend has proposed to you, a spontaneous yes with a happy smile is good policy - but only if you have been waiting for the proposal anyhow; otherwise some careful deliberation whether this is the right companion for the rest of your life is in order. Consequently, appropriate problem solving modes selectively draw on input, processing, and output modules, in light of the features of the task at hand. The problem solving mode thus is the link between capabilities and tasks.

\section{b) Resources}

Resources are listed as a separate component in our model since they need not be internal. Technical progress has left not a single internal resource without an external substitute. Moreover, external resources often are not just substitutes but superior to internal resources. An obvious example is the addition of large numbers, where a calculator will outperform the human brain in both speed and reliability. Normally, internal and external resources have their comparative strengths and weaknesses. A computer may have higher storage capacity than human memory, but is worse at reconfiguring its stock of knowledge according to changes in interest or in the environment.

There are two principal sources of external resources: technology and people. Technical resources that facilitate decision-making or problem solving are as old as writing and printing. Four eyes see more than two, and experts can bring their specialized knowledge and professional experience to a task. Groups are able to exploit the power of averaging out random error if each member reports an independent observation. Organised groups can extend the gains from specialisation to task specific interaction.

\section{c) Processing Modules}

While there are a great variety of internal and external resources, the number of processing modules is strictly confined. Figure 2 provides a complete list. 


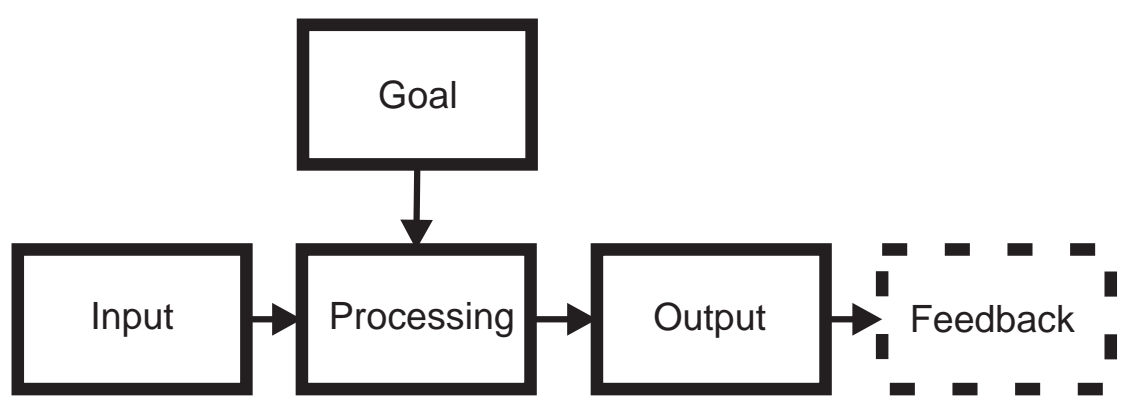

Figure 2

Processing Modules

Input from the environment is mentally processed in the light of a goal to generate an output. Optionally, feedback informs the individual about consequences resulting from the output.

The operation of each of these modules has a wide range. At their very basic, an individual hears the horn of a car and jumps to the sidewalk. One piece of sound triggers the simple decision rule "flee to safety," which the individual executes on the spot. At the opposite end of the range of complexity, an individual may read in the newspaper that, due to demographic change, the pay-as-you-go pension system is no longer sustainable. This piece of information induces the individual to consider alternative sources of a retirement income. She consults some of the relevant literature, asks the works council about the pension plan of her company, and calculates her freely available income. With this information in mind, she gains an understanding of the problem of intertemporal choice she faces. How much consumption today is she willing to sacrifice for greater comfort after retirement? How long is she likely to earn a regular income? How long will she live? Is it important that her children inherit a fortune? How should today's savings be best invested? She thus goes through a complex process of generating further input and producing the criteria that ultimately direct her choice of alternative investments.

\section{d) Tasks}

Ultimately, institutional designers are not interested in how a decision maker approaches and solves a problem or makes a decision, but instead in the socially relevant behaviour that results from this meta-decision. Our model therefore has a task component.

This component borrows from political science. For a much more aggregate actor, namely the legislator, political science faces the same conceptual challenge. It must single out the necessary components of the decision-making process. The tool for doing this is called the policy cycle. While there are many versions of this cycle, a fairly stylised version (May and Wildavsky 1978) has stood the test of time and lends itself to the analogy with individual decision makers in which we are interested. Figure 3 translates it into what we call the problem solving cycle. 


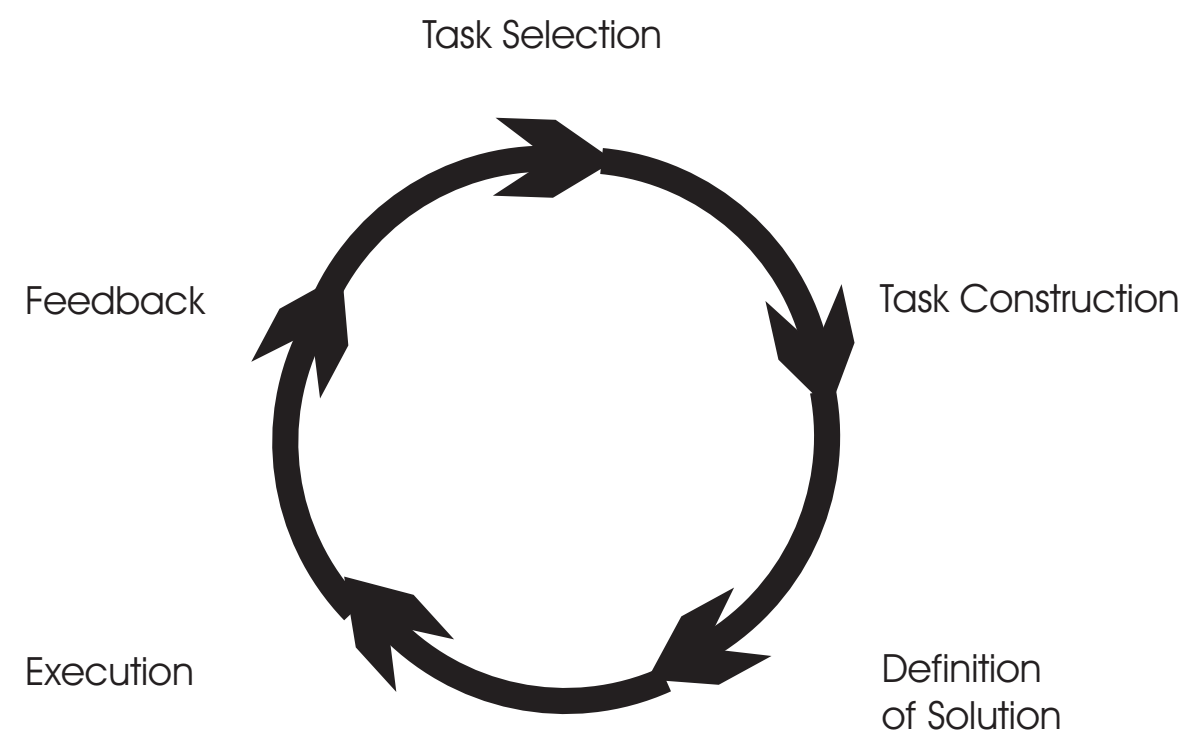

Figure 3

Problem Solving Cycle

The cycle starts on the top, with task selection. On a normal day, an individual has to make hundreds, if not thousands of decisions. Should I turn right or left on my way to the train station? Should I help myself to another cup of coffee? Should I speak up at the business meeting? Should I prepare for tomorrow's lesson? Should I have an argument with my neighbour? Should I prolong the contract with the gym? Should I buy a new car? Should I accept the offer for a new job? Should I undergo elective surgery? Should I break up with my partner? Even with the help of external resources, considering all of them immediately can be beyond the individual's capacity. If so, the individual must engage in task selection.

The shorthand for task selection is the question: Which of the many issues deserving of my attention should I consider at this point in time? This decision is influenced by both the situation I currently find myself in and by my values, needs, and goals. But what exactly is "this issue"? Often, at the beginning this is far from clear. Since problem definition therefore is not merely a mechanical affair, the model speaks of task construction. Is there a choice between exogenously specified alternatives, or is the solution space open? What are the relevant constraints? Is there a benchmark for a good solution, or is defining a benchmark part of the task? Are the relevant facts known or at least knowable, or must the decision be taken under uncertainty? Task construction need not be dictated by the environment. Due to the severe limitations on logical reasoning, individuals often construct as a decision under uncertainty what might be solved logically (Oaksford and Chater 1994). For instance, in situations of strategic interaction, they do not calculate through complex game trees, but simply ask: is this person trustworthy? This ability to construct the task in different, and often simpler ways makes it possible to rely on simple heuristics for decision-making (Gigerenzer, Todd et al. 1999).

Once the task has been construed, the decision maker is left with three questions: is the issue worth producing any output at all? If so, what are the available options? Which of these options 
is to be preferred? Answering these three questions is what we call the definition of the solution. At this stage, the individual must define the output space. Often she is not confined to choosing among preconfigured options, but can use her creativity. In assessing the options, she needs a normative benchmark. Again, this is not necessarily a given. Often the individual is able to change the benchmark in light of the task at hand (Klein 1998).

The reason for making execution a separate element of the model is the possibility to entrust execution to external resources. Relying on technology for execution has become ubiquitous. Whenever the individual does not physically execute the decision, there is the same potential of an implementation deficit that has kept political scientists busy for decades (Winter 1975; Mayntz 1980). There also are implementation deficits of a psychological nature, as discussed by (Gollwitzer and Schaal 1998).

While outcome evaluation is not always sought, because negative evaluations reflect badly on the problem solver and might reduce his external standing and self-esteem, evaluation is necessary for learning from one's own experiences. In many contexts, the sensory system and memory do not give the individual much choice on the matter. The individual often is not able to avoid learning about and from failure, and recalling the bad experiences when a similar task comes up again is virtually automatic. Moreover, evaluation can be entrusted to technology and to outsiders, if necessary even against the will of the individual, as in the case of tax auditors who are legally mandated to check the accounting practices of companies.

\section{e) Problem Solving Modes}

In our model, problem solving modes link processing modules to task characteristics. Depending on the resources they muster, modules can meet different performance standards. Ideally, the problem solving mode exactly matches the requirements of the task. Conversely, it is the plurality of task characteristics that explains the plurality of problem solving modes which, in turn, allows individuals to reach better decisions. Not being confined to the one cognitively-effortful all-purpose analytic tool suggested by the rational-economic model empowers individuals to save internal and external resources, which increases their overall problem solving capacity.

Strictly speaking, these considerations are not sufficient to justify problem solving modes as a separate component of the model. It would be enough to directly link specific processing modules to task characteristics. Problem solving modes are a necessary model component, however, if the normal decision how to decide does not directly match modules to task characteristics, but is confined to choosing among preconfigured problem solving modes, which is precisely our claim. While novel problem solving modes can be made up on the spot and from scratch, engaging the individual in the full analytic deliberation of rational-economic man, this is probably an exception. Instead, most people most of the time can be expected to engage in some matching of existing, tried-and-true problem solving modes to the presenting task and available resources and to engage in the problem solving mode that provides the best match. 
The metaphor of the mental tool box is telling. When one wants to hang a painting, one selects a hammer and a nail. Only in extraordinary circumstances would one start to construct a new tool. Likewise, when facing a decision task, individuals typically check the problem solving modes available to them. Only in exceptional situations will they try to forge a new problem solving mode. When individuals decide how to decide, the default is choosing the most appropriate preconfigured problem solving mode, given the characteristics of the task.

Relying on preconfigured problem solving modes saves mental and external resources. The decision how to decide reduces to a mere matching task, where the domain of the task at hand is matched against the domains in which existing problem solving modes have performed well. This presentation of the issue invites the classification of problem solving modes as skills (Anderson 2000:chapter 9). A skill is a chain of mental and physical modules that are chunked together. The skill is stored in memory as just one unit. If it is retrieved, it unrolls in its entirety. To a large extent, this is indeed true of problem solving modes. They are learned and acquired with experience, rather than being innate. Moreover, not all individuals hold the same problem solving modes in their mental tool boxes.

The contents of the box depends on the individual decision-making and problem solving history. Professional deformation is an obvious illustration. A trained economist has a proclivity to see strategic interaction everywhere. This may induce her to use her game-theoretical reasoning skills for decision-making where others would have relied on intuition. More importantly, to the extent that problem solving modes are skills, the individual can learn how to make better decisions. Specifically, when our economist learns through evaluation and feedback that the performance of her chosen problem solving mode was poor, she has one of two options. She can switch to a different problem solving mode in future instances, in which case she has learnt something about the proper domain of the problem solving mode. Alternatively, the bad experience may help her to modify the chosen problem solving mode in some way to improve its performance in future applications.

No craftsman has an unlimited number of tools. Likewise the number of problem solving modes to which a given individual has access is probably limited, even though there is no abstract bound to the number of problem solving modes which human decision makers may have at their disposition. When task characteristics change over time or technological or institutional innovations provide new opportunities, human creativity will generate more appropriate problem solving modes.

Table 2 illustrates the concept of a preconfigured problem solving mode with its different stages by four examples from different content domains. The examples range from utmost simplicity (responding to a fire alarm in a building) to high complexity (responding to a fire as a member of a fire brigade). The reaction to a fire alarm should be almost automatic. Selling land should be a deliberate affair. The other two examples of problem solving modes are meant to combine deliberate with intuitive components. While the first two problem solving modes do not involve evaluation, it is crucial in the other two cases. The modes for responding to a fire alarm and for 
selling land a fairly fixed, while the modes for driving and for a fire brigade are highly plastic. While the mode for selling land heavily relies on external resources, those are at most secondary in the reaction to a fire alarm, and in driving behaviour.

\begin{tabular}{|c|c|c|c|c|c|}
\hline Domain & $\begin{array}{c}\text { Task } \\
\text { Selection }\end{array}$ & $\begin{array}{c}\text { Task } \\
\text { Construction }\end{array}$ & $\begin{array}{l}\text { Definition of } \\
\text { Solution }\end{array}$ & Execution & Evaluation \\
\hline fire alarm & $\begin{array}{l}\text { override any } \\
\text { other task }\end{array}$ & $\begin{array}{l}\text { immediately } \\
\text { leave the } \\
\text { building }\end{array}$ & $\begin{array}{l}\text { check emergency } \\
\text { exit signs }\end{array}$ & go to staircase & - \\
\hline selling land & $\begin{array}{l}\text { do not } \\
\text { multitask }\end{array}$ & $\begin{array}{l}\text { legally } \\
\text { standardised }\end{array}$ & see notary public & go & - \\
\hline $\begin{array}{l}\text { defensive } \\
\text { driving }\end{array}$ & $\begin{array}{l}\text { do not } \\
\text { answer the } \\
\text { phone }\end{array}$ & safety first & $\begin{array}{l}\text { adjust driving } \\
\text { to weather } \\
\text { conditions }\end{array}$ & manipulate car & $\begin{array}{l}\text { permanently } \\
\text { readjust to } \\
\text { traffic situation }\end{array}$ \\
\hline fire brigade & $\begin{array}{l}\text { 1. save lives } \\
\text { 2. fight fire }\end{array}$ & $\begin{array}{l}\text { 1. extinguish } \\
\text { 2. prevent from } \\
\text { spreading }\end{array}$ & $\begin{array}{l}\text { - } \text { water or foam? } \\
\text { access from } \\
\text { within the } \\
\text { building? } \\
\text { - precautionary } \\
\text { measures }\end{array}$ & $\begin{array}{l}\text { coordinate } \\
\text { action with } \\
\text { members of } \\
\text { brigade }\end{array}$ & $\begin{array}{l}\text { permanently } \\
\text { readjust }\end{array}$ \\
\hline
\end{tabular}

Table 2

Problem Solving Modes: Illustrations

\section{f) Choice Among Problem Solving Modes}

The plurality of problem solving modes gives humans a rich set of options for solving problems, often with less effort than required by an exhaustive analysis, but could also be seen as adding to the decision load, as resources must be invested into the metadecision among problem solving modes. It is not likely, however, that the brain goes through complex calculations for each and every of the many metadecisions of how to decide that an individual takes on a day. Instead, we hypothesize that the decision how to decide is usually taken by default.

The basic idea is culled from a model of heuristic decision-making developed by (Engel 2006). Figure 4 displays its structure, as adapted to our problem of meta-choice. 


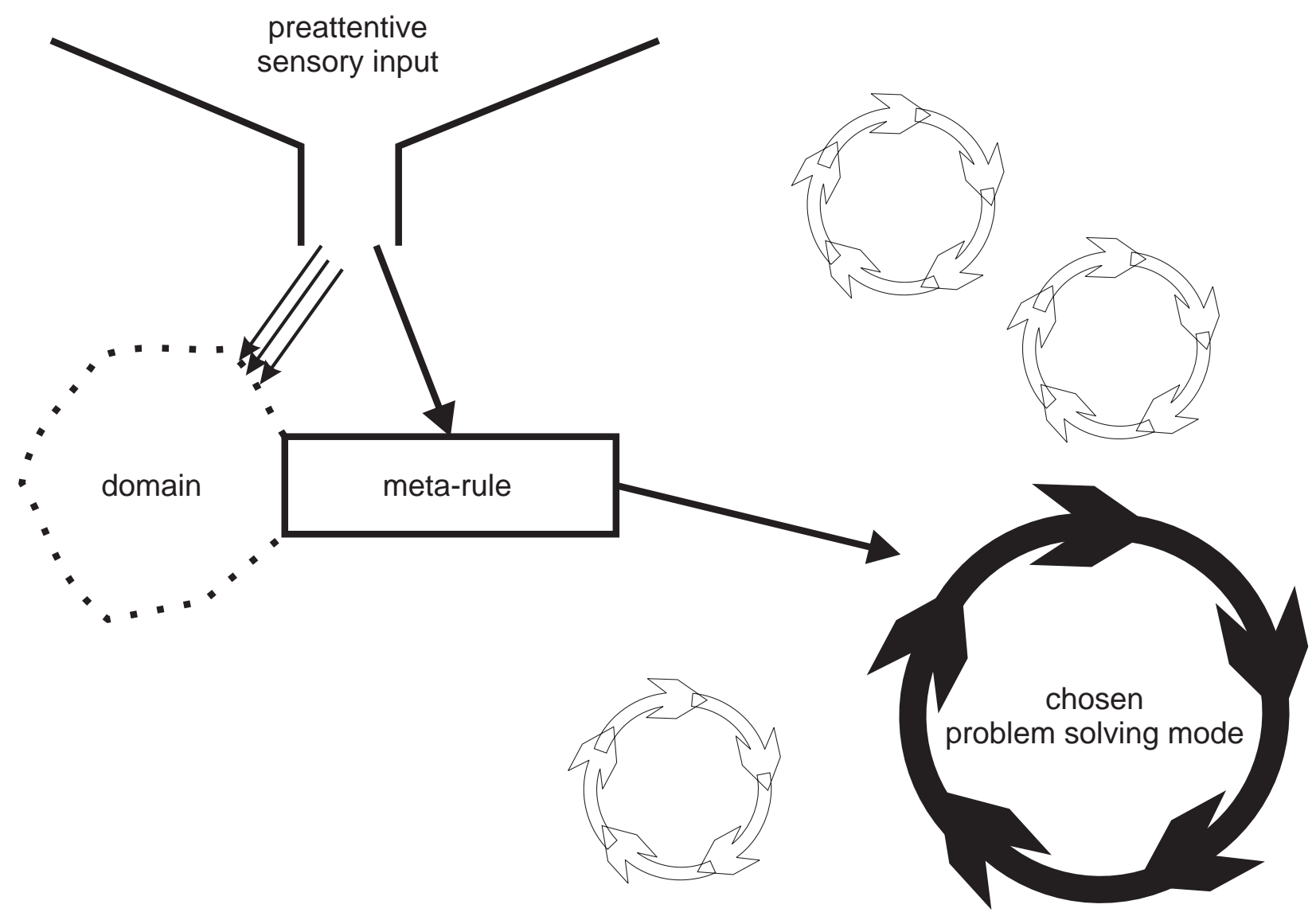

Figure 4

Choice Among Preconfigured Problem Solving Modes

The model states that the information about the task and the environment is processed according to an ex ante defined decision rule that maps input conditions to problem solving modes. Specifically, if the definitional cues that the meta-rule specifies for a problem solving mode are present, the corresponding mode is applied. When selecting the problem solving mode, the individual thus does not check whether this mode is in line with her goals. This is not to say that goals were irrelevant for this choice, but that, in the concrete meta-choice, the check against the goals has been incorporated and reduced to a mere matching exercise, where the goal component has been replaced by a "domain" component. For a predetermined problem-solving mode to be applied, not only its definitional cues must be found in the input provided by the task environment, but other features of the situation must also point to the applicability of the problem solving mode. While the cues are definitional, the domain is described in a less precise way. The description could be by exemplars (Anderson 2000:350-352) or, more likely, by schemas (Bartlett 1932:199-204; Goldstein and Weber 1997:598) (also see Schlicht 1998:chapter 7 on rules based on schemas) or by scripts (Schank and Abelson 1977). For instance, before overtaking, the driver would check whether this is ordinary traffic. The schema for "ordinary" traffic might encompass: Am I on the motorway? Are there two or more lanes on the street? Can I look ahead more than 100 yards? Is there no rain or ice on the road? Is there little traffic? Do I know the street? Am I not tired? Not all, but a sufficient number of these questions would have to be answered in the 
positive. If so, the two definitional cues would be: is there traffic on the opposing lane? Are others overtaking at the same time? If both are answered in the negative, the driver would apply her overtaking routines, regulating all the necessary mental and motor activity.

Consequently, all the individual has to do when faced with a decision task is checking for descriptions of domains stored in memory. If such a description is found, she determines the problem solving mode without further ado. There is thus no weighing of pros and cons of different problem solving modes in the concrete decision situation. Specifically, such weighing is only undertaken if the individual has not previously settled down for tackling a certain class of tasks by a certain problem solving mode. However, if no appropriate problem solving mode emerges by this matching process, we assume the default mode for choosing among problem solving modes to be some analytic form of weighing arguments. This need not necessarily be done consciously, however. Emotions might also play a role in this.

\section{Access Points for Institutions}

The purpose of our model has been to map out the access points for institutional intervention. In principle, intervention may affect the use of an internal or external resource and the selection of a specific version of different processing module(s) or of an entire problem solving mode. Thereby, institutional intervention may in principle impact on every element of the problem solving cycle.

\section{a) Illustrations from Institutional Practice}

It is relatively easy for institutions to make additional external resources available for the problem solving activities of their addressees. For instance, anti-discrimination legislation obliges employers to keep records. That way, universities become aware of the fact that many more women graduate than start an academic career, and many more become assistant professors than get tenure. The intervention matters since statistics outperform intuition (Meadow and Sunstein 2001). Institutions may also impose the assistance of experts. For instance, house owners in some countries are not allowed to maintain their chimneys, but have to engage the services of a professional chimney sweeper. Access to internal resources is less easily influenced from the outside, but skill building is one way to do so. Regular fire drills provide an illustration. They are meant to inscribe a script in people's memories, which would unroll almost automatically in an emergency situation.

Other institutions provide their addressees with the content of entire processing modules. Take another precautionary measure, the posting of standardised signs for emergency exits, as an example for an institution offering a module for input. Due to the signs, individuals have no need for orientation. Should an emergency break out, they just follow the green signs. Likewise, institutions may impact on the module for output. For instance, safety legislation specifies that electric hedge shears have to be designed in such a way that they can only be handled with two 
hands. This reduces the risk that the gardener negligently injures herself or a bystander. Another piece of legislation makes long checklists mandatory in aircraft maintenance. Such lists make sure that all the safety relevant information is properly processed. Much of criminal law can be read as an attempt at influencing the goal module. Individuals are threatened with severe sanctions if they let feelings like vengeance or avidity gain the upper hand. Finally, institutions may impose an evaluation and feedback module. This is, for instance, part of Eco management and audit schemes (EC OJ 2001 L 114/1).

Institutions can influence all elements of the problem solving cycle. The siren of the ambulance is a tool for changing other drivers' task selection. They no longer concentrate on reaching their destination, but drive to the shoulder. A good example for the impact of institutions on task construction stems from waste management legislation. This legislation serves two purposes: to protect the environment from emissions on the waste path, and to reduce the use of natural resources. Both purposes are best served if products are designed in a waste friendly manner. Ideally, producers should thus construct their task in research and development differently. Legislation tries to bring this result about by obliging producers to take their products back at the end of the product cycle.

There are two strategies for institutions to change how their addressees define the solution. The easier strategy aims at reducing the choice set. Take waste management again. Through advertising campaigns, environmental agencies have tried to establish the social norm "do not litter." Adding a normatively more desirable course of action to the individual's choice set is more demanding. But in some countries, waste management authorities have indeed educated households to separate waste into fractions, like paper or plastics.

Institutions frequently impact on the execution of tasks. Again a negative strategy may be distinguished from a positive one. Internal sovereignty implies that government has a monopoly on the exercise of physical power. For ordinary citizens, this excludes a large set of technologies for executing their decisions. Conversely, fire fighters are trained to go into burning buildings, which others could only do at a much greater risk for life and limb. Finally, institutions may impose evaluation. This is, for instance, done if the university president makes student evaluation of courses and professors mandatory.

Regularly, however, institutions do not only try to modify the resources or processing modules used for problem solving, or individual elements of the problem solving cycle. Instead, their goal is to endow their addressees with entire new problem solving modes, or to modify their choice among existing problem solving modes.

Many institutions serve as rationalisers. They shift problem solving to the careful and deliberate weighing of pros and cons. Many have observed that markets have this effect (see only Becker 1962; Plott 1986). The most important effect of transferring interaction to a market is motivational. Acting on a market visibly raises stakes (Smith 1989; Smith 1991; Smith 1994). Markets also shape motivation. Strong pro-social motivation is not likely to survive (Hoffman and Spitzer 
1985). But in markets, outright selfishness or even irrational anti-social behaviour does not pay either. Markets therefore also serve as training grounds for the basic rules of social interaction (Henrich and Boyd 2005; Jankowiak 2005). The cognitive effects of markets do result from the fact that transactions happen on a formally or informally organised market (Engel and Schweizer 2002). The institutional framework thus helps market participants build mutual expectations.

Other institutions aim at routinisation. Professionalisation does exactly this (Gehlen 1960:71; Goldstein and Hogarth 1997:29). It is a rich institutional arrangement. Its most important formal component is a legal barrier to market entry. More and more professions have come under this regime. Being a doctor, a dispensing chemist, an architect, a structural engineer, an attorney or a notary public requires formal admission. The admission requirement makes it possible to impose formal training on future professionals. Moreover, many professions are organised into chambers. This brings professionals under the purview of a formally organised peer group (Battaglini, Benabou et al. 2002). Both training and peer group control allow for a dense net of informal rules, dos and don'ts and standards of best practise. Moreover, within professions, social status is closely linked to obedience to these rules, and to participation in their implementation.

Yet other institutions bring about automatisation. The driving school example from the introduction fits here. The very purpose of this intervention is to endow future drivers with a whole set of very simple decision rules. Stop when the traffic light turns red. Slow down when it starts to rain. Check the mirror before overtaking another car.

\section{b) Implications for Institutional Design}

Not all institutions are designed. Neither social norms nor customary law are the direct result of purposeful intervention. Yet many institutions are indeed introduced with a very precise purpose in mind. Suppose the designer pursues an ultimate goal that would be best served by changing how the addressees decide to decide. How could this designer bring the change about? The answer largely depends on a further question: does the designer have time, or must she attain the ultimate goal by this one intervention, i.e., ad hoc? At this point, the policy relevance of our main claim becomes visible. Since problem solving modes are typically preconfigured, ad hoc interventions will usually not be able to directly target a resource, a module or an element from the problem solving cycle. If intervention is, or must be, ad hoc, it usually is confined to targeting the choice among preconfigured problem solving modes.

If the public is scandalised by a social ill, the media may demand that penalties be raised. This is a way of visibly raising stakes. Higher stakes focus self-critical attention to the decision-making process (Arkes 1991). They induce people to prepare more intensely (Tetlock 1983a), to be more open to facts (Lerner, Goldberg et al. 1998), to take more of the available information into account (Tetlock 1983b; Tetlock and Boettger 1989) and to show greater internal consistency (Hagafors and Brehmer 1983; Ashton 1992). All these effects at the level of behaviour can be traced back to the fact that higher stakes make addressees switch to deliberate reasoning as the problem solving mode. A justification requirement has a similar effect. Cognitively, justification 
makes the individual aware of the actual complexity of the task (Cvetkovich 1978; Hagafors and Brehmer 1983; Weldon and Gargano 1988). Motivationally, the justification requirement makes accountability salient (Hagafors and Brehmer 1983).

Deliberate reasoning is, however, not the only and often perhaps not the best problem solving mode that can be triggered when immediate intervention is required. In experiments, psychologists often induce participants to use different decision modes by such manipulations as time pressure (e.g. Maule, Hockey et al. 2000) or distraction by multitasking (e.g. Bishop 2001). Institutional intervention can learn from these examples that it is possible to change the situation such that addressees match the task with another preconfigured problem solving mode.

Immediate intervention can also exploit the fact that most problem solving modes are skills. Skills are domain specific. Skills are stored in memory as procedural knowledge. This means that institutions can target recall from memory. Memory recall is guided by two factors: its base rate of activation, and the recency of previous recall (Anderson 2000:chapter 8). The latter is open to ad hoc intervention. As research on priming demonstrates, previous activation of a fact or a skill makes its subsequent recall and use more likely. Previous activation does not need to target precisely the same item whose subsequent privileged recall is desired, as memory activation spreads in a network like manner (Collins and Loftus 1975).

It is not always necessary for institutions to change behaviour ad hoc. Long-term intervention is acceptable if it is sufficient to change a long-term behavioural trend. This presupposes that society tolerates temporary deviations from the social optimum. Under these more favourable conditions, institutional designers may pursue one of two strategies. The more profound strategy aims at endowing addressees with additional problem solving modes. The less profound strategy increases the availability of a previously existing problem solving mode in a new area.

In the interest of reaching these long-term goals, interventions may be more or less direct. The most direct intervention is imposed training, as in driving school or in the obligation to go to professional schools. A more indirect strategy is applicable if the addressees have the desired problem solving mode in their tool box, but do not employ it to the socially desired degree. A practically important case are problem solving modes with a pronounced intuitive component, as perceived accountability induces individuals to work harder, but not necessarily smarter (Payne, Bettman et al. 1988:200). As a result, decision quality improves for standard tasks, but may deteriorate for unusual tasks (Pelham and Neter 1995:582; Hogarth, Gibbs et al. 1997:247-249). Subjects become more likely to exhibit dominant responses (Lerner and Tetlock 1999:259). They focus on what they are good at (Hogarth, Gibbs et al. 1997:247). In such a situation, institutional intervention must help addressees build trust in the power of their intuitions. To than end, institutions often shield addressees from potentially negative consequences of their action. The business judgement rule from corporate law (Greenfield and Nilsson 1997) can be brought under this rubric, as well as rules that shelter public officials from personal responsibility, or rules that prohibit court intervention into matrimonial affairs, and in the education of children by their parents. 
Going back to the examples from Table 2, Table 3 summarizes the access points and the most important elements of the respective institutional arrangements.

\begin{tabular}{|c|c|c|c|}
\hline Domain & $\begin{array}{l}\text { Shaping Problem } \\
\text { Solving Mode }\end{array}$ & $\begin{array}{l}\text { Triggering Problem } \\
\text { Solving Mode }\end{array}$ & $\begin{array}{l}\text { Maintaining } \\
\text { Acceptance }\end{array}$ \\
\hline fire alarm & $\begin{array}{l}\text { compulsory } \\
\text { rehearsals }\end{array}$ & $\begin{array}{l}\text { acoustic and optic } \\
\text { symbols }\end{array}$ & justificatory stories \\
\hline selling land & $\begin{array}{l}\text { - } \text { compulsory rules } \\
\text { of property law } \\
\text { - notary public } \\
\text { - land register } \\
\end{array}$ & estate agent & (taken for granted) \\
\hline defensive driving & driving school & $\begin{array}{l}\text { - } \text { torts } \\
\text { - limited insurance } \\
\text { coverage }\end{array}$ & $\begin{array}{l}\text { governmental } \\
\text { impact on formation } \\
\text { of social norms }\end{array}$ \\
\hline fire brigade & $\begin{array}{l}\text { - } \text { selection } \\
\text { - professional } \\
\text { training } \\
\end{array}$ & $\begin{array}{l}\text { - } \text { hierarchical } \\
\text { organisation } \\
\text { - peer group }\end{array}$ & team spirit \\
\hline
\end{tabular}

Table 3

Institutional Interventions

\section{Conclusion}

Our paper has attempted to make the following argument. In many contexts, institutions are not confined to just changing behaviour; instead they can and should attempt to control and modify the way in which decisions are made and implemented. This is a demanding, but not an impossible goal. Institutions have a number of access points available to them for this purpose. Specifically, institutions may pursue two different strategies. For ad hoc interventions, they may modify the task environment in ways that trigger a different preconfigured problem solving mode. On a longer-term basis, they may increase the repertoire of problem solving modes available to addressees, and they may change the likelihood that specific problem solving modes are used.

Our conceptual model of the way in which individuals solve problems and make decisions is intended to show that institutions are not restricted to affect only available resources, processing modules, or specific elements of the problem solving cycle. We argue that the easiest access point for institutional intervention is the meta-selection of an entire problem solving mode. As problem solving modes typically are domain-specific acquired skills that muster appropriate resources in light of task characteristics, institutional interventions should aim to modify the task environment in ways that will increase selection of a socially more desirable mode or to invest in the establishment and automatisation of new problem solving modes in situations where socially desirable modes are not part of people's cognitive tool box. 


\section{References}

Anderson, John R. (2000). Learning and Memory. An Integrated Approach. New York, Wiley.

Arkes, Hal R. (1991). "Costs and Benefits of Judgment Errors - Implications for Debiasing." Psychological Bulletin 110(3): 486-498.

Ashton, Robert H. (1992). "Effects of Justification and a Mechanical Aid on Judgment Performance." Organizational Behavior and Human Decision Processes 52: 292-306.

Bandura, Albert (1986). Social Foundations of Thought and Action. A Social Cognitive Theory. Englewood Cliffs, N.J., Prentice-Hall.

Bartlett, Frederic C. (1932). Remembering. A Study in Experimental and Social Psychology. Cambridge, [Eng.], The University Press.

Battaglini, Marco, Roland Benabou, et al. (2002). Self Control in Peer Groups.

Becker, Gary Stanley (1962). "Irrational Behaviour and Economic Theory." Journal of Political Economy 70: 1-13.

Bishop, Karen (2001). "Working Smart and Working Hard. The Effects of Entrepreneurial Multi-tasking and Intuitive Activities on Venture Performance." Dissertation Abstracts International Section A: Humanities and Social Sciences 61(9-A): 3645.

Bohner, Gerd (2001). Attitudes. Introduction to Social Psychology. M. Hewstone and W. Stroebe. Oxford, Blackwell: 239-282.

Chaiken, Shelly and Yaacov Trope (1999). Dual-process Theories in Social Psychology. New York, Guilford Press.

Collins, Allan M. and Elizabeth F. Loftus (1975). "A Spreading-Activation Theory of Semantic Processing." Psychological Review 82: 407-428.

Corrado, Michael Louis (1999). "Addiction and Responsibility. An Introduction." Law and Philosophy 18: 579-588.

Cvetkovich, George (1978). "Cognitive Accommodation, Language, and Social Responsibility." Social Psychology 41: 149-155.

Damasio, Antonio (2000). The Feeling of What Happens. Body and Emotion in the Making of Consciousness. San Diego, Calif., Harvest.

DiMaggio, Paul J. (1998). "The New Institutionalisms. Avenues of Collaboration." Journal of Institutional and Theoretical Economics 154: 696-705. 
DiMaggio, Paul J. and Walter W. Powell (1991). Introduction. The New Institutionalism in Organizational Analysis. W. W. Powell and P. J. DiMaggio. Chicago, University of Chicago Press: $1-38$.

Engel, Christoph (2005). Generating Predictability. Institutional Analysis and Institutional Design. Cambrige, Cambridge University Press.

Engel, Christoph (2006). Social Dilemmas Revisited from a Heuristics Perspective. Heuristics and the Law. G. Gigerenzer and C. Engel. Cambridge, Mass., MIT Press: 61-85.

Engel, Christoph and Urs (eds.) Schweizer (2002). "Organising and Designing Markets." Journal of Institutional and Theoretical Economics 158: 1-5.

Epstein, Seymour (1994). "Integration of the Cognitive and the Psychodynamic Unconscious." American Psychologist 49: 709-724.

Evans, Jonathan St.B.T. and David E. Over (1997). "Are People Rational ? Yes, No, and Sometimes." Psychologist: 403-406.

Furubotn, Eirik Grundtvig and Rudolf Richter (1997). Institutions and Economic Theory. The Contribution of the New Institutional Economics. Ann Arbor, University of Michigan Press.

Gehlen, Arnold (1960). Mensch und Institutionen. Anthropologische Forschung. Zur Selbstbegegnung und Selbstentdeckung des Menschen. A. Gehlen. Hamburg, Rowohlt: 69-77.

Gigerenzer, Gerd and Christoph Engel, Eds. (2006). Heuristics and the Law. Boston, MIT Press.

Gigerenzer, Gerd and Reinhard Selten, Eds. (2001). Bounded Rationality. The Adaptive Toolbox. Cambridge, MA, MIT Press.

Gigerenzer, Gerd, Peter M. Todd, et al. (1999). Simple Heuristics that Make us Smart. New York, Oxford University Press.

Goldstein, William M. and Robin M. Hogarth (1997). Judgment and Decision Research. Some Historical Context. Research on Judgement and Decision Making. W. M. Goldstein and R. M. Hogarth. Cambridge, Cambridge University Press: 3-65.

Goldstein, William M. and Elke U. Weber (1997). Content and Discontent. Indications and Implications of Domain Specificity in Preferential Decision Making. Research in Judgement and Decision Making. W. M. Goldstein and R. M. Hogarth. Cambridge, Cambridge University Press: 566-617.

Gollwitzer, Peter M. and Bernd Schaal (1998). "Metacognition in Action. The Importance of Implementation Intentions." Personality and Social Psychology Review 2: 124-136. 
Greenfield, Kent and John E. Nilsson (1997). "Gradgrind's Eduction. Using Dickens and Aristotle to Understand (and Replace?) the Business Judgement Rule." Brooklyn Law Review 63: $799-859$.

Hagafors, Roger and Berndt Brehmer (1983). "Does Having to Justify one's Judgments Change the Nature of the Judgment Process?" Organizational Behavior and Human Decision Processes 31: 223-232.

Hall, Peter and Rosemary C.R. Taylor (1996). "Political Science and the Three New Institutionalisms." Political Studies 44: 936-957.

Henrich, Joseph and Robert Boyd (2005). "'Economic Man' in Cross-Cultural Perspective. Behavioral Experiments in 15 Small-Scale Societies." Behavioral and Brain Sciences 28: 795-815.

Hodgson, Geoffrey Martin (1988). Economics and Institutions. A Manifesto for a Modern Institutional Economics. Philadelphia, University of Pennsylvania Press.

Hodgson, Geoffrey Martin (2004). "Reclaiming Habit for Institutional Economics." Journal of Economic Psychology 25: 651-660.

Hodgson, Geoffrey Martin (2006). "What Are Institutions?" Journal of Economic Issues 40: 125 .

Hoffman, Elizabeth and Matthew L. Spitzer (1985). "Entitlements, Rights, and Fairness. An Experimental Examination of Subject's Concepts of Distributive Justice." Journal of Legal Studies 14: 259-297.

Hogarth, Robin M., Brian J. Gibbs, et al. (1997). Learning from Feedback. Exactingness and Incentives. Research on Judgement and Decision Making. W. M. Goldstein and R. M. Hogarth. Cambridge, Cambridge University Press: 244-284.

James, William (1893). Psychology: Briefer Course. New York,, H. Holt and company.

Jankowiak, William (2005). "Market Integration, Cognitive Awareness, and the Expansion of Moral Empathy." Behavioral and Brain Sciences 28: 826-827.

Jolls, Christine and Cass R. Sunstein (2006). "Debiasing Through Law." Journal of Legal Studies 35: 199-241.

Klein, Gary (1998). Sources of Power. How People Make Decisions. Cambridge, MA., MIT Press.

Langlois, Richard N. (1998). Rule-Following, Expertise, and Rationality. A New Behavioural Economics? Rationality in Economics. Alternative Perspectives. K. Dennis. Boston, Kluwer: 55-78. 
Lerner, Jennifer S., Julie H. Goldberg, et al. (1998). "Sober Second Thought. The Effects of Accountability, Anger, and Authoritarianism on Attributions of Responsibility." Personality and Social Psychology Bulletin 24: 563-574.

Lerner, Jennifer S. and Philip E. Tetlock (1999). "Accounting for the Effects of Accountability." Psychological Bulletin 125: 255-275.

Lessig, Lawrence (1999). Code and other Laws of Cyberspace. New York, Basic Books.

Loasby, Brian J. (1999). Knowledge, Institutions, and Evolution in Economics. London ; New York, Routledge.

Mantzavinos, Chrysostomos (2001). Individuals, Institutions, and Markets. Cambridge, UK, Cambridge University Press.

March, James G. and Chip Heath (1994). A Primer on Decision Making. How Decisions Happen. New York, Free Press.

March, James G. and Johan P. Olsen (1989). Rediscovering Institutions. The Organizational Basis of Politics. New York, Free Press.

Maule, A. John, G. Robert Hockey, et al. (2000). "Effects of Time-Pressure on Decision-making under Uncertainty: Changes in Affective States and Information Processing Strategy." Acta Psychologica 104: 283-301.

May, Judith V. and Aaron B. Wildavsky (1978). The Policy Cycle. Beverly Hills, Sage.

Mayntz, Renate (1980). Implementation politischer Programme. Empirische Forschungsberichte. Königstein/Ts., Athenäum.

Meadow, William and Cass R. Sunstein (2001). "Statistics, not Experts." Duke Law Journal 51: 629-646.

Nee, Victor (1998). Sources of the New Institutionalism. The New Institutionalism in Sociology. M. C. Brinton and V. Nee. New York, Russell Sage Foundation: 1-16.

Nooteboom, Bart and Irma Bogenrieder (2003). Change of Routines. A Multi-Level Analysis.

Oaksford, Mike and Nick Chater (1994). "A Rational Analysis of the Selection Task as Optimal Data Selection." Psychological Review 101: 608-631.

Ostrom, Elinor (2005). Understanding Institutional Diversity. Princeton, Princeton University Press.

Payne, John W., James R. Bettman, et al. (1988). "Adaptive Strategy Selection in Decision Making." Journal of Experimental Psychology 14: 534-552. 
Payne, John W., James R. Bettman, et al. (1993). The Adaptive Decision Maker. Cambridge, Cambridge University Press.

Pelham, Brett and Efrat Neter (1995). "The Effect of Motivation on Judgment Depends on the Difficulty of the Judgment." Journal of Personality and Social Psychology 68: 581-594.

Peters, B. Guy (1999). Institutional Theory in Political Science. The New Institutionalism. London, Pinter.

Plott, Charles R. (1986). Rational Choice in Experimental Markets. Rational Choice. The Contrast between Economics and Psychology. R. M. Hogarth and M. W. Reder. Chicago, University of Chicago Press: 117-144.

Prelec, Drazen and Richard J. Herrnstein (1991). Preferences or Principles. Alternative Guidelines for Choice. Strategy and Choice. R. Zeckhauser. Cambridge, MIT Press: 319-340.

Rutherford, Malcolm (1994). Institutions in Economics. The Old and the New Institutionalism. Cambridge England, Cambridge University Press.

Schank, Roger C. and Robert P. Abelson (1977). Scripts, Plans, Goals, and Understanding. An Inquiry into Human Knowledge Structures. Hillsdale, Erlbaum.

Schlicht, Ekkehart (1998). On Custom in the Economy. Oxford, Clarendon Press.

Simon, Herbert A. (1986). Decision Making and Problem Solving. Report of the Research Briefing Panel on Decision Making and Problem Solving. N. A. o. Sciences. Washington, National Academy Press.

Simon, Herbert Alexander (1990). "Invariants Of Human Behavior." Annual Review of Psychology 41: 1-19.

Smith, Vernon L. (1989). "Theory, Experiment and Economics." Journal of Economic Perspectives 3(1): 151-169.

Smith, Vernon L. (1991). "Rational Choice. The Contrast between Economics and Psychology." Journal of Political Economy 99: 877-897.

Smith, Vernon L. (1994). "Economics in the Laboratory." Journal of Economic Perspectives 8: 112-131.

Stanovich, Keith E. and Richard F. West (2000). "Individual Differences in Reasoning. Implications for the Rationality Debate?" Behavioral and Brain Sciences 23: 645-665.

Strack, Fritz and Roland Deutsch (2002). Reflective and Impulsive Determinants of Social Behaviour. 
Tetlock, Philip E. (1983a). "Accountability and Complexity of Thought." Journal of Personality and Social Psychology 45: 74-83.

Tetlock, Philip E. (1983b). "Accountability and the Perseverance of First Impressions." Social Psychology Quarterly 46: 285-292.

Tetlock, Philip E. and Richard Boettger (1989). "Accountability. A Social Magnifier of the Dilution Effect." Journal of Personality and Social Psychology 57: 388-398.

Vanberg, Victor (2002). "Rational Choice vs. Program-Based Behavior. Alternative Theoretical Approaches and their Relevance for the Study of Institutions." Rationality and Society 14: 7-54.

Veblen, Thorstein (1898). "Why is Economics not an Evolutionary Science?" Quarterly Journal of Economics 12: 373-397.

Weber, Elke U. (1998). "From Shakespeare to Spielberg. Predicting Modes of Decision Making." Presidential Address. Annual Meeting of the Society for Judgement and Decision Making, Dallas, Texas.

Weber, Elke U., Daniel R. Ames, et al. (2004). "'How Do I Choose Thee? Let me Count the Ways': A Textual Analysis of Similarities and Differences in Modes of Decision-making in China and the United States." Management and Organization Review 1(1): 87-118.

Weber, Elke U. and Christopher K. Hsee (2000). "Culture and Individual Decision Making." Applied Psychology 49: 32-61.

Weber, Elke U. and Patrizia G. Lindemann (2007). From Intuition to Analysis. Making Decisions with Your Head, Your Heart, or by the Book. Intuition in Judgement and Decision Making. H. Plessner, C. Betsch and T. Betsch. Mahwah, NJ, Lawrence Erlenbaum.

Weldon, Elizabeth and Gina M. Gargano (1988). "Cognitive Loafing. The Effects of Accountability and Shared Responsibility on Cognitive Effort." Personality and Social Psychology Bulletin 14: 159-171.

Winter, Gerd (1975). Das Vollzugsdefizit im Wasserrecht. Ein Beitrag zur Soziologie des Öffentlichen Rechts. Berlin, Schmidt. 